\title{
A Mathematical and Conceptual Model Regarding Social Inclusion and Social Leverage
}

\author{
Giovanni E. Reyes \\ Ph.D. Full, Tenure professor, \\ Universidad del Rosario, Bogotá, Colombia \\ Mark Govers \\ Ph.D. Tenure Professor, \\ University of Maastricht \\ Dirk Ruwaard \\ Ph.D. Tenure Professor, \\ University of Maastricht
}

Doi: $10.2478 / \mathrm{mjss}-2018-0043$

\begin{abstract}
This article discusses a comprehensive conceptual mathematical model to specify main theoretical concepts and their relationships, regarding social inclusion and social leverage. The particular elements of the model are related to: (i) key aspects of theoretical principles; (ii) major links among principal aspects; and (iii) interrelations regarding social and economic issues within any particular society. One of the principal aims of this research is going beyond the strictly economic elements, to complement a more holistic perspective with social aspects and public policy. This study is part of a broader research project that studies social investment in Latin America, particularly focused in the health sector. More specifically, this study will identify relationships between variables and indicators of social inclusion and social leverage, as basis for carrying out empirical studies on investments that Latin American countries make in health services. The model presented here allows the identification of elements of differentiated public policy, the role of public services aimed to assist especially the most vulnerable social sectors and the support of such services in relation to a country's competitiveness, social well-being and sustainable basis of human development.
\end{abstract}

Keywords: social inclusion, social leverage, social mathematical model

\section{Introduction}

In terms of this study, it will be understood that social inclusion is the condition in which there is an effective participation of the diverse groups that constitute society in its collective well-being. In this condition, the joint effort of citizens plays a crucial role in the combined exercise of social rights and duties. Complementary, it will be understood that social leverage is the set of actions, activities and projects that aim to achieve and give sustainability to the condition of social inclusion. This social leverage can be developed by public entities, by companies and private initiative entities or by the action of non-profit organizations (Baas, 2002; Reyes, 2010; Stiglitz, 2013).

In reference to social sciences in general, and development studies in particular, mathematical models not only allow to identify relationships between variables and components, 
but also the priorities of those relationships in order to explain, interpret and predict phenomena. Mathematical models allow us to recognize social processes, the structural and conjunctural factors that have influences in outcomes, and how is the performance of components that are vital for such processes to take place. Mathematical models can be vital tools for identifying mechanisms that belong to the complexities of social phenomena (Acemoglu, 2012; North, 2011; Todaro, 2011).

In this study, the essential components of the model will first be identified. From there, both main and complementary relationships are formulated. From the identification of these components, the equations of the model are developed. What is important to keep in mind here is that the formulation of the model tends to: (i) have an integral view of the phenomenon in terms of its dynamics; (ii) differences regarding applications of social leverage as an important aspect of public policy; and (iii) provide a coherent vision between economic and social aspects in terms of the sustainable development of a society (Baker 1998; Nussbaum, 2004; Ruger, 2010).

\section{Basic Research Model}

All in all, and taking into consideration elements of the previous section of this study, the key assumption of this research is that as more economic growth a country would have, the more investment it will be devoted to its national health care system (NHCS). As a result, poverty levels will decline over time, and the index of human development (HDI) will increase.

Conversely, with less economic growth it is expected that a particular country would dedicated less resources for its NHCS. As a result, poverty levels will remain steady -or they will increase. In addition to that, HDls will be almost unaffected or, in the worst of the cases, they will decrease (Moore, 2009; Levy, 2007; Bailey, 2008). ${ }^{1}$ Figure 1 shows the mentioned general relationships among variables.

The aforementioned insights are, in this study, formalized in a theoretical research model that is based on the following proposition: when you have conditions of poverty and economic growth, countries will increase their investments in the national health care system, a factor which in turn will lead to increases in human development indexes.

Based on Figure 2, the basic research model to be applied in this study is:

Static original conditions:

$\left(\alpha_{1} \delta P_{i y}\right)+\left(\alpha_{2} \delta Y_{i y}\right)=\left(\alpha_{3} \delta I N H C S_{i y}\right)+\left(\alpha_{4} \delta H D I_{i y}\right)$

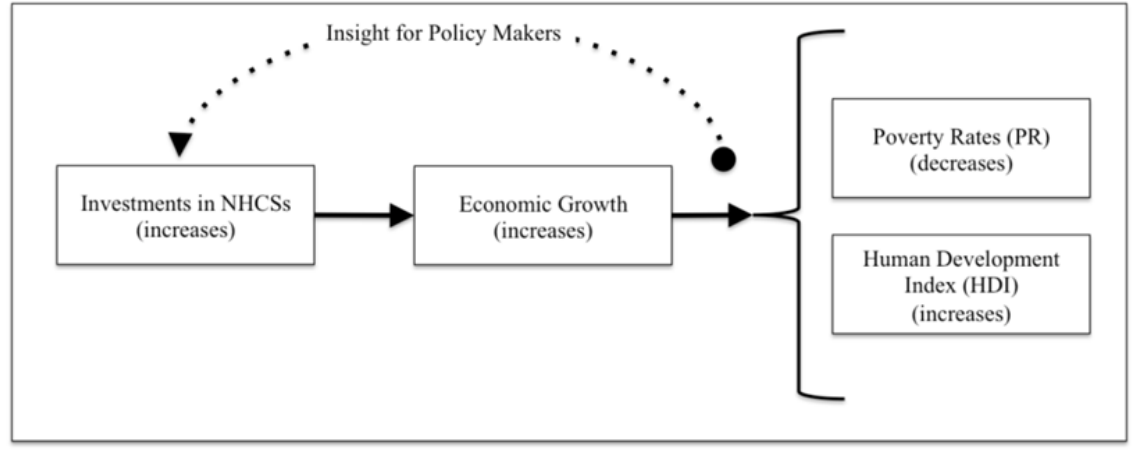

Figure 1: Relationships among Main Variables

Source: This study's elaboration.

\footnotetext{
${ }^{1}$ For a discussion concerning interaction of factors acting as mutually reinforcing components -usually evaluated through techniques of regressive factor analysis- see Moore, M. (2009) Globalization and Social Change (New York: Elseiver); Levy, M. (2007) Social Patterns and Problems of Modernization. (Englewood Cliffs, New Jersey: Prentice Hall); and, Bailey, K. (2008) Methods of social research.(New York: The Free Press). One key element of these authors is the perspective of the political, social, cultural and economic effects of national and world wide factors on development conditions belonging to a particular nation; especially for those in the less developed world.
} 
Where the alpha signs refer to the general parameters of model; $P$ and $Y$ refer to poverty and economic growth conditions, respectively to a country (i) having conditions of specific year $(y)$. INHCS is the indicator investment in national health care systems for any particular country, and $H D I$ refers to human development index.

Dynamic expected-aggregated consequences:

$$
\int_{t i=1}^{t i=n}\left(\alpha_{2} \delta Y_{i y}\right)_{t i}+\int_{t i=1}^{t i=n}\left(\alpha_{3} \delta I N H C S_{i y}\right)_{t i} \Rightarrow \nabla \int_{t i=1}^{t i=n}\left(\alpha_{1} \delta P_{i y}\right)_{t i}+\Delta \int_{t i=1}^{t i=n}\left(\alpha_{4} \delta H D I_{i y}\right)_{t i}
$$

Here we have what is the central model in terms of interaction of fundamental variables. As a country has economic growth $(Y)$, and in addition it has investment in its national health care system (INHCS) it will have decreasing levels of poverty $(P)$ and rising standards concerning the human development index $(H D I){ }^{2}$

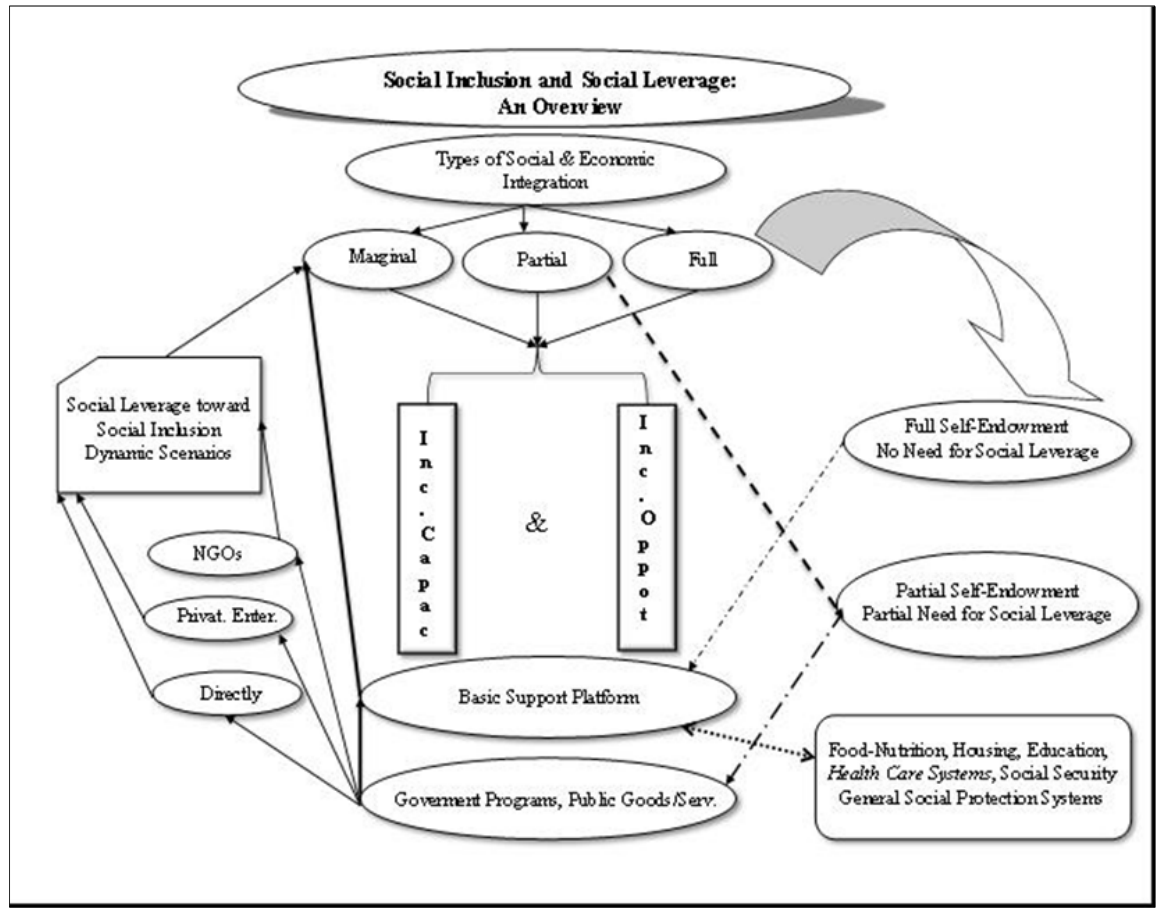

Figure 2: Social Inclusion and Social Leverage: An Overview Source: This study's elaboration.

${ }^{2}$ For example, in terms of use of resources -for specific areas of economic growth- "sacrifices" of the present would be in function of future stages of development. At the macroeconomic level of countries we have the basic model:

$Y=C+I+G+X-M$

From this model it is possible to capture the influence of consumption, level of investment, public expenditures, exports and imports -or net exports. In reference to macro multipliers from the aforementioned model we have:

$Y=\frac{\bar{C}+\bar{G}+\bar{I}+\bar{X}-\bar{M}}{(1-c-i+m)}$

From this statement, the higher the marginal trend to consumption or investment, for instance, the higher would be the impact on economic growth and thus in feasibility, or potentials, to achieve higher standards of development. For more discussions of the relationship between social and economic factors with development and global conditions see: Stiglitz, J. (2003) The Happy Nineties and the Seed of Destruction (New York: Random), especially Chapter IV: Deregulation, pp. 127-141, 148-152; Chapter VI: Banks and the Financial Crisis, pp. 183-187, 201-212;and Chapter VIII: Risk as a Way of Life, pp. 228-235, 239-241, an 244-248. 
Summary of parameters and trends:

$$
\begin{aligned}
& \alpha_{1}, \triangleleft 0 \ldots \ldots \ldots \ldots . .(3) \\
& \alpha_{2}, \alpha_{3}, \alpha_{4} \triangleright 0 \ldots \ldots \ldots . .(4) \\
& \left(\delta P_{i y}\right) \triangleleft 1 \ldots \ldots \ldots . .(5) \\
& \left(\delta Y_{i y}\right) \triangleright 1 \ldots \ldots \ldots . .(6) \\
& \left(\delta I N H C S_{i y}\right) \triangleright 1 \rightarrow \cong K \ldots \ldots \ldots .(1 . \\
& \left(\delta H D I_{i y}\right) \triangleright(O C)_{i y} \rightarrow \Delta \rightarrow \cong 1 . . .
\end{aligned}
$$

Here it is important to keep in mind that the only parameter to expect would be for decreasing is poverty rate; meanwhile the other parameters will increase, as a result of having more social resources from the rates of economic growth.

This complete condition is going to contribute the rising of the human development index $(H D I)$ which in turn would show the trend of stabilization as it arrive to very high levels - toward 1 . This phenomenon is according to the law of diminishing returns. Levels of investment in national health care systems (INHCs) will also achieve particular levels of stabilization.

Explicit trends:

$$
\begin{aligned}
& \left(\alpha_{1} \delta P_{i y}\right)_{t+1}-\left(\alpha_{1} \delta P_{i y}\right)_{t} \triangleleft 0 \ldots \ldots \ldots . .(9) \\
& \left(\alpha_{2} \delta Y_{i y}\right)_{t+1}-\left(\alpha_{2} \delta Y_{i y}\right)_{t} \triangleright 0 \ldots \ldots \ldots . . .(10) \\
& \left(\alpha_{3} \delta I N H C S_{i y}\right)_{t+1}-\left(\alpha_{3} \delta I N H C S_{i y}\right)_{t} \triangleright 0 \rightarrow \cong K . \\
& \left(\alpha_{4} \delta H D I_{i y}\right)_{t+1}-\left(\alpha_{4} \delta H D I_{i y}\right)_{t} \triangleright(O C)_{i y} \rightarrow \Delta \rightarrow \cong 1 .
\end{aligned}
$$

Based on the explicit trends, this study shows the expected dynamic performance of variables comparing two points in time; it is expected that poverty rates will decline, economic growth will increase; we will have increases in the levels of investment concerning national health care systems and human development indexes as well (Todaro, 2011; Zimmermann 2006).

\section{Specific Relationships' Model}

$$
T N \prod_{i=1}^{i=n}(\Sigma s g)_{i}=\operatorname{PriG}+\operatorname{PubG}\left\{\int_{i=1}^{i=n} \pi S G_{i}\right\} \ldots . \text { (13) }
$$

Here we have the TN, total net score of social wellbeing; that is the gross total minus the amount of replenishing capital, which is the equivalent of the reposition investment. This aspect is referring to the total social groups $(\mathrm{sg})$. On the other hand of the equation we have the private (PriG) and the public (PubG) goods and services which in turn is impacting the aggregate (integral) value of social wellbeing of specific groups.

$$
\int_{i=1}^{i=n} \pi S G_{i}=\left\{\begin{array}{c}
\left(\sum_{i=1}^{i=n} \pi M a r g\right)\left(S L_{t}\right)+\left(\sum_{i=1}^{i=n} \pi P I n\right)(P S L)_{P a r}+\cdots \\
\ldots\left(\sum_{i=1}^{i=n} \pi F I n\right)(\xi S L)_{\phi}
\end{array}\right\} \ldots . .
$$

From model 14, we have the explicit disaggregation of social groups concerning their social and economic integration within a particular social and economic system. Consequently, we have marginal groups (Marg) those who are partially integrated (Pin) and the full integrated social sectors (Fin). All of them have their reference to the social leverage which will be with inverse intensity in reference to the level of social integration.

That means, the more complete social leverage will be aimed to the marginal groups, the partial social support for the partially integrated and practically lacking support for those groups which have enough economic capacity to face their real demand or needs. Because those fully integrated groups have outstanding economic capacity, they are able to transform their real demand into effective demand within social and economic system (Till, 2005; Rahim, 2010).

Social leverage from the institutional framework, that is the set of public institutions, we have variables contained in equation 15. Because of the aforementioned inverse relationship between economic capacity and social leverage provided by public institutions, we have that one of the core condition for (15) is the decreasing degree of coefficients: $\alpha_{1>} \alpha_{2>} \alpha_{3}$.

$$
S L(G o b)=\alpha_{1}(S L)(\Sigma \Pi m a r g)+\alpha_{2}(S L)(\Sigma \Pi \text { ParInt }) \ldots+\alpha_{3}(S L)(\Sigma \Pi F u l l I n t) \ldots
$$


Given:

$\alpha_{1>} \alpha_{2>} \alpha_{3}$

$\&$ :

$\alpha_{3 \simeq} \frac{\delta\{(S L)(\Sigma \pi F u l l i n t)\}}{\delta\{(S L)(\mathrm{Gob})\}} ;$

$\operatorname{Lim}(\delta\{(S L)(\Sigma \pi F u l l I n t)\}) \rightarrow \emptyset \ldots(16)$

The everyday level of social leverage will trend to the limit cero, as is presented in equation 16 , regarding institutional support for the fully integrated social sectors. In addition, we need to keep in mind that those sectors with more wealth would be those who make more contributions for the fiscal system that is the tax structure. As this last mentioned feature is real, we can have the evidence that the fiscal system is progressive.

$$
\int_{i=1}^{i=N} N \pi(S G)_{i} \simeq \int \kappa(G N P) \ldots . .(17)
$$

Equations from 17 to 23 display a crucial topic: the relationship between social welfare of social wellbeing with the gross national product that is the aggregated economic capacity of production a society can count on. This is vital because all social goods, public services and in general all forms and means or channels for delivering social support need to be part of an economic sustainable system.

Equation 17 shows the aggregated value that social wellbeing has with the total economic production within a society; as one can see, from equation 18, the specific version for portraying gross national product (GNP) is the expenditure arrangement. Hence, we have four main sectors: consumption (C) -from families or homes- investment (I) -from companies or firms- government spending $(G)$, which includes operation costs and public investment; and net exports -external sector characterized by exports minus imports $(X-m)$ (Maddison, 1991; Meyer, 1977).

$G N P=Y=C+I+G+X-m \ldots(18)$

$\int k(G N P) \simeq\left(C^{k c}+c Y\right)+\left(I^{k I}+I Y\right)+\left(G^{k G}+G Y\right)+\left(X^{k x}+X Y\right) \ldots-\left(m^{k m}+m Y\right) \ldots . .(19)$

Equation 19 shows a more specific representation of the 18 proposition. Here the basic macroeconomic model contains which are the constant values of each one of the expenditures consumption, government, investment and net exports- and the marginal propensity for growing concerning individually the aforementioned variables as well.

In general, the more increases the gross national product, the more will the amount of each of its components in absolute terms, even we can keep constant the proportion of marginal propensity to grow. For example, for exports, the constant value within an economy is $X^{k x}$ and $X Y$ the marginal propensity. GNP is also represented by $\mathrm{Y}$.

From equation 20 to 23, it is possible to see the deductive procedure to identify what is known by the macroeconomic multipliers. As it is evident, all the particular components of GNP or $Y$, as they increase their marginal propensities to grow, $Y$ will have a positive variation. This feature is true with the exception of imports $(\mathrm{m})$; as they growth, $\mathrm{Y}$ and therefore the total production of a country will fall.

$$
\begin{aligned}
& k(G N P) \simeq\left(C^{k c}+I^{k I}+G^{k G}+X^{k x}-m^{k m}\right)+c Y+I Y+G Y+X Y \ldots-m Y \ldots . \\
& \mathrm{K}=\left(C^{k c}+I^{k I}+G^{k G}+X^{k x}-m^{k m}\right) \ldots(21) \\
& \text { Then: } \\
& \mathrm{Y}+c Y+I Y+G Y+X Y-m Y=\mathrm{K} \ldots(22) \\
& \text { This implies: }
\end{aligned}
$$$$
\mathrm{Y}=\frac{K}{(1+c+I+G+X-m)} \ldots
$$

This complete model for identifying the multipliers model, especially when it is calculated for long-run effects, is calculated using procedures belonging to comparative statics. In the core sense of these calculations one needs to take into account how variations of endogenous variables change in the long run. This concrete application is known as the implicit function theorem.

Multiplier effects have a decisive impact on GNP rates of growth, and consequently in the sustainability or capacity to keep up in time, resources for public or private institutions aid, that is the complete level of social leverage a particular country can carry out (Gilpin, 2001; Bulmer, 2005).

The key variable to support a sustainable rate of growth in the GNP is investment, since this aspect is essential for creating productive jobs and employment. So to obtain that scenario any 
particular country needs to attract capital in the real sphere of economy. Equation 24 shows six strategic characteristics to assure productive capital goes to any economic system.

$\int k($ GNP $) \simeq \alpha_{1}($ PolSta $)+\alpha_{2}($ MacSta $)+\alpha_{3}($ Inst $)+\alpha_{4}($ CulFac $) \ldots+\alpha_{5}($ HumRes $)+\alpha_{6}$ (PhInfr $) \ldots$ (24)

From equation 24 , it is evident the influence of (i) political stability; (ii) macroeconomic stability; (iii) institutional social inclusive frame and predominance of the rule of law; (iv) cultural factors; (v) capacity and competences of human resources, and (vi) development and competitive presence of physical infrastructure -that is: PolSta, MacSta, Inst, CulFac, HumRes, and PhInfr, respectively. The particular and overall influence of those factors can explain why capital resources goes rather to Singapore, than Haiti, to only present and illustrative case.

Following the Solow's theorem in terms of the influence of capital -technical influences- and labor, it is possible to present equation 25 , which shows the possibility of having certain amount of resources for social leverage growth comparatively taken into account two periods in time $(t \& t-1)$

$T N \prod_{i=1}^{i=n}(\Sigma s g)_{i}=\left\{k_{1}(\operatorname{Cap}(\text { Techn }))+k_{2}(\text { Lab })\right\}_{t} \ldots-\left\{k_{1}(\operatorname{Cap}(\text { Techn }))+k_{2}(\text { Lab })\right\}_{t-1} \ldots . .(25)$

In order to have a sustainable dynamic scenario or conditions for providing social leverage growth, it is indispensable to get the following assumptions:

$T N \prod_{i=1}^{i=n}(\Sigma s g)_{i}>\phi \ldots . .(26)$

$T N \prod_{i=1}^{i=n}(\Sigma s g)_{i}>\wedge$ Soc. Needs.....

$T N \prod_{i=1}^{i=n}(\Sigma s g)_{i}>\wedge$ Pop. Growth

That is: social leverage growth, overtime, must be larger than 0 , social needs and the rate of population growth (Acemoglu, 2000; Piketty, 2013).

$S L($ Gob $)=\alpha_{1}($ Food \& Nutr $)+\alpha_{2}$ (Hous) $+\alpha_{3}($ Educ $)+\alpha_{4}($ HCSys $)+\alpha_{5}($ SocSec $)+\alpha_{6}($ GenSocProSyst $) \ldots . .(29)$

Finally, equation 29 of this model exposes several aspects which in turn constitute social leverage from public institutions. Those elements are: (i) food and nutrition; (ii) housing; (iii) education; (iv) health care systems; (v) social security; and (vi) general social protection systems that is: Food \&Nutr; Hous; Educ; HCSys; SocSec; and GenSocProSyst, respectively.

Everything being taken into account, after the aforementioned considerations -regarding formal mathematical representations of relationships from Figure 2: social inclusion \& social leverage- the exacting links that should be studied -as part of the follow up activities- are:

(a) General connections:

(a.1.) $\left(\alpha(\text { INHCS })_{i j}\right) \cong\left(\alpha(\text { Povert .Rates })_{i j}\right) \ldots \ldots \ldots . . .(30)$

(a.2.) $\left(\alpha(I N H C S)_{i y}\right) \cong\left(\alpha(H D I s)_{i y}\right)$.

(a.3.) $\left(\alpha(\text { Povert.Rates })_{i j}\right) \cong\left(\alpha(H D I s)_{i j}\right)$

Where, as it was said before, the particular acronyms are: INHCS, stands for investment in national health care systems; Povert., Rates, for poverty rates; and HDIs, for human development indexes.

(b) Specific connections:

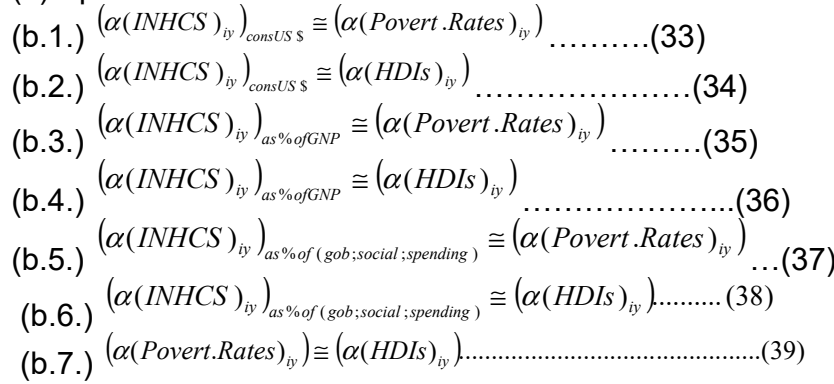

In this set of particular connections, it is taken into account, that the concrete indicator of investment in the national health care systems (INHCS), will be characterized by three ways: (i) constant US dollars (cons US\$); (ii) as percentage of gross national product (gnp); and (iii) as percentage of government social spending (gob; social spending). 


\section{Final Considerations and Conclusions}

The mathematical model presented here allows the identification of the main variables and their corresponding indicators, regarding social leverage activities and the condition of social inclusion in a given society. At the beginning, as a first stage, a general and particular relationships of economic and social variables and indicators are presented.

In a second phase, the specific aspects related to the economic and social articulation of the different population groups in a country are made explicit. These social groups may be fully, partially or marginally integrated in social and economic terms. As these groups have more economic integration -usually through employment or owing enterprises- they are more able to have access to goods and services in order to satisfy their effective demand in the social and economic scenarios of a given society.

On the other hand, to the extent that the groups have marginal living conditions, more emphasis is required on social leverage activities. This aid is generally implemented through government transfers, but can also be established through the actions of non-profit entities or the cooperation of private businesses.

The mathematical model identified here includes the components and direct relationships for social leverage, but also the conditions of economic growth. For the latter, aspects of production in a country have been addressed as fundamental elements of macroeconomics. The purpose of this last issue is to underline, as part of the model, about economic sustainability of a society that decides to incorporate all the groups that compose it, to the development efforts for achieving higher degrees of human development.

\section{References}

Acemoglu, D. \& Robinson, J. (2000). Why did the West extend the franchise? Democracy, inequality, and growth in a historical perspective. Quaterly Journal of Economics 115 (4),1167- 1200.

Acemoglu, D. \& Robinson, J. (2012). Why Nations Fail? The Origins of Power, Prosperity and Poverty. New York: Crown Books.

Baas, S. (2002) Sustainable Development Strategies. London, OECD.

Bailey, K. (2008) Methods of social research. New York: The Free Press.

Baker, D. et. al. (1998) Globalization and progressive economic policy. Cambridge, U.K.: Cambridge University Press.

Bulmer, M. \& Warwick, D. (2005).Social Research in Developing Countries, Surveys and Censuses in the Third World. Boston: Taylor \& Francis Group.

Gilpin, R. (2001) Global Political Economy: Understanding the International Economic Order.Princeton: Princeton University Press.

Habermas, J. (2008) Structural Transformation of the Public Sphere. Boston: MIT Press.

Lareau, A. \& Horvat, E. (1999). Moments of social inclusion and exclusion: Race, class, and cultural capital in family-school relationships. Sociology of Education 72 (1), 37-53.

Levy, M. (2007)Social Patterns and Problems of Modernization. Englewood Cliffs, New Jersey: Prentice Hall.

Maddison, A. (1991). Dynamic forces in capitalist development. Oxford: Oxford University press.

Meyer, J. et.al. (1977). Institutionalized organizations: Formal structure as myth and ceremony. American Journal of Sociology, 83, 340-363.

Moore, M. (2009) Globalization and Social Change. New York: Elseiver.

North, D. (2011) A General Theory of Institutional Change. New York: Random.

Nussbaum, M. (2004). 'Beyond the Social Contract: Capabilities and Global Justice. An Olaf Palme Lecture, Oxford, 19 June 2003.' Oxford Development Studies, 32(1).

Piketty, T. (2013) "Capitalism in the XXI Century"New York: Belknap Press.

Rahim, M. (2010) Poverty and Sustainable Development. London: Edward Elgar.

Reyes, G. (2001). Globalization and Latin American Economies 1960-1995: A Network Analysis Model and Implications for Economic Growth. (Doctoral Dissertation, University of Pittsburgh, Hathi Trust Digital Library; see from catalog: http://catalog.hathitrust.org/Record/007250231).

Reyes, G. (2010) "Theoretical Basis of Crisis of Legitimacy and Implications for Less Developed Countries: Guatemala as a Case of Study" in Journal Tendencias, Colombia, 11(1), 142-163.

Ruger, J. (2004). 'Ethics of the social determinants of health.' Lancet 364, 1092-97. 
Ruger, J. (2010). 'Health capability: conceptualisation and operationalisation. American Journal of Public Health. 100, 41-49.

Sen, A. (2011) Development as Freedom. New York: Random.

Stiglitz, J. (2003) The Happy Nineties and the Seed of Destruction. New York: Random.

Stiglitz, J. (2013) Price of Inequality: How Today's Divided Society Endangers Our Future. New York: Norton \& Company.

Till, M. (2005, June). Assessing the housing dimension of social inclusion in six European countries. Innovation: The European Journal of Social Sciences 18 (2), 153-181.

Todaro, M. (2011) Economic Development. New York: Prentice-Hall, 11nd. Edition.

Zimmermann, B. (2006). 'Pragmatism and the Capability Approach: Challenges in Social Theory and Empirical Research.' European Journal of Social Theory 9(4), 467-484. 